Published in final edited form as:

Injury. 2016 January ; 47(1): 244-249. doi:10.1016/j.injury.2015.11.006.

\title{
Fall injuries in Baghdad from 2003 to 2014: results of a randomized household cluster survey
}

\author{
Barclay T Stewart, MD, MScPH, \\ Department of Surgery, University of Washington, Seattle, WA, USA; School of Public Health, \\ Kwame Nkrumah University of Science and Technology, Kumasi, Ghana; Department of Surgery, \\ Komfo Anokye Teaching Hospital, Kumasi, Ghana \\ Riyadh Lafta, MBChB, \\ Department of Community Medicine, Al Munstansiriya University, Baghdad, Iraq \\ Sahar A Esa Al Shatari, PhD, \\ Human Resources Development and Training Center, Iraq Ministry of Health, Baghdad, Iraq \\ Megan Cherewick, MPH, \\ Department of International Health, Johns Hopkins Bloomberg School of Public Health, Baltimore, \\ MD, USA
}

\begin{abstract}
Abraham Flaxman, PhD, Department of Global Health, University of Washington, Seattle, WA, USA; Institute for Health Metrics and Evaluation, Seattle, WA, USA
\end{abstract}

\begin{abstract}
Amy Hagopian, PhD, MHA,
Department of Global Health, University of Washington, Seattle, WA, USA; Department of Health Services, University of Washington, Seattle, WA, USA

Gilbert Burnham, MD PhD, and

Department of International Health, Center for Refugee and Disaster Response, Johns Hopkins Bloomberg School of Public Health, Baltimore, MD, USA

\section{Adam L Kushner, MD, MPH}

Surgeons OverSeas (SOS), New York, NY, USA; Department of International Health, Johns Hopkins Bloomberg School of Public Health, Baltimore, MD, USA; Department of Surgery, Columbia University, New York, NY, USA
\end{abstract}

\section{Abstract}

Introduction-Falls incur nearly 35 million disability-adjusted life-years annually; $75 \%$ of which occur in low- and middle-income countries. The epidemiology of civilian injuries during conflict is relatively unknown, yet important for planning prevention initiatives, health policy and

Corresponding author: Barclay T Stewart, MD MscPH, University of Washington, Department of Surgery, 1959 NE Pacific St., Suite BB-487, PO Box 356410, Seattle, WA 98195-6410, Phone: 206-543-3680, stewarb@uw.edu.

Publisher's Disclaimer: This is a PDF file of an unedited manuscript that has been accepted for publication. As a service to our customers we are providing this early version of the manuscript. The manuscript will undergo copyediting, typesetting, and review of the resulting proof before it is published in its final citable form. Please note that during the production process errors may be discovered which could affect the content, and all legal disclaimers that apply to the journal pertain. 
humanitarian assistance. This study aimed to determine the death and disability and household consequences of fall injuries in post-invasion Baghdad.

Methods-A two-stage, cluster randomized, community-based household survey was performed in May of 2014 to determine the civilian burden of injury from 2003 to 2014 in Baghdad. In addition to questions about household member death, households were interviewed regarding injury specifics, healthcare required, disability, relatedness to conflict and resultant financial hardship.

Results-Nine hundred households totaling 5,148 individuals were interviewed. There were 138 fall injuries (25\% of all injuries reported); fall was the most common mechanism of civilian injury in Baghdad. The rate of serious fall injuries increased from 78 to 466 per 100,000 persons in 2003 and 2013, respectively. Fall was the most common mechanism among the injured elderly (i.e. $\ 65$ years; $15 / 24$ elderly unintentional injuries; $63 \%$ ). However, 46 fall injuries were children aged $<15$ years (49\% of unintentional injuries) and 77 were respondents aged 15 - 64 years (36\%). Respondents who spent significant time within the home (i.e. unemployed, retired, homemaker) had three times greater odds of having suffered a fall injury than student referents (aOR 3.34; $95 \%$ CI $1.30-8.60$ ). Almost $80 \%$ of fall injured were left with life-limiting disability. Affected households often borrowed substantial sums of money (34 households; $30 \%$ of affected households) and/or suffered food insecurity after a family member's fall (52; 46\%).

Conclusion-Falls were the most common cause of civilian injury in Baghdad. In part due to the effect of prolonged insecurity on a fragile health system, many injuries resulted in life-limiting disabilities. In turn, households shouldered much of the burden after fall injury due to loss of income and/or medical expenditure, often resulting in food insecurity. Given ongoing conflict, civilian injury control initiatives, trauma care strengthening efforts and support for households of the injured is urgently needed.

\section{Keywords}

fall; aging; Iraq; conflict; war; epidemiology; community assessment; global surgery

\section{Introduction}

Injuries account for $11 \%$ of the global disease burden. ${ }^{1}$ Falls are the second leading cause of unintentional injury worldwide and are increasing in frequency given aging populations. ${ }^{2}$ This burden rests disproportionately on low- and middle-income countries (LMICs), which harbor $75 \%$ of the 34 million disability-adjusted life years incurred annually from fall injuries. $^{3}$

Iraq is a middle-income country that has been plagued by decades of conflict. In addition to acts of violence, insecurity has disrupted injury prevention strategies, safe infrastructure, maintenance of a culture of safety, and the fragile health system. ${ }^{4,5}$ Because of this, risk of injury and subsequent death or disability are high in Iraq. ${ }^{4-9}$ In 2010, injury incurred more than 4,100 disability-adjusted life-years (DALYs) per 100,000 persons in Iraq. For comparison, the rate of DALYs incurred from injury in Lebanon, a Middle Eastern country with an equivalent gross domestic product per capita, was $2,441 . .^{10,11}$ Intentional injuries and fatalities related directly to conflict (e.g. gun shots, bomb blasts) may represent only a 
fraction of the total injury burden during conflict, particularly among civilians. ${ }^{4}$ Therefore, estimating the burden of civilian intentional and unintentional injuries may provide a more accurate assessment of the effect of conflict on a population in crisis than focusing on conflict-related injuries alone. ${ }^{4,6,7,12}$

A cross-sectional household cluster survey performed in Baghdad in 2009 reported that the injury incidence was 58 per 1,000 persons (worldwide rate of injuries is 0.61 per 1,000 persons). ${ }^{4,13}$ Falls were the most common injury reported in Iraq in all age groups (30\% of all injuries) and were more common than road traffic injuries (9\% of all injuries), gunshots (6\%), stabbings (2\%) and explosions (7\%) combined. This unusual epidemiology highlights the importance of understanding direct and indirect civilian injury burden during wartime prior to adopting under-informed injury prevention or health system strengthening interventions. $^{5}$

To address the lack of data on civilian traumatic death and disability in Baghdad postinvasion, a two-stage cluster randomized, community-based survey on injuries that occurred from 2003 to 2014 was performed in May of 2014. This report details the death and disability, healthcare received and household consequences from fall injuries. By doing so, better estimates of the cumulative effect of insecurity on civilian injuries could be determined. Such estimates might better inform injury control initiatives, health policy and humanitarian relief planning.

\section{Methods}

\section{Study design}

A team of international and Iraqi public health and trauma experts with experience from previous two-stage cluster study designs in Iraq, Rwanda and Sierra Leone developed the survey strategy. $7,14,15$ A survey instrument was adapted from the World Health Organization's community injury survey guidelines and the Surgeons OverSeas Assessment of Surgical Need (SOSAS). ${ }^{14-16}$ The instrument was translated into Arabic, back translated to assure accuracy and piloted for utility and validity. The final version was designated the Surgeons OverSeas Injury Survey (SOSINJ).

A two-stage randomized 30 cluster by 30 households sample was performed. Baghdad was divided into 14 administrative districts and sectors and 30 random clusters were chosen using Google Earth ${ }^{\mathrm{TM}}$. Clusters were delineated based on the 2011 population estimates for administrative units in Baghdad. Data were obtained from the Iraqi Central Organization for Statistics and Information Technology and Ministry of Health. ${ }^{17}$ Five clusters were randomly replaced due to security concerns or being located proximate sensitive military facilities a priori.

\section{Data collection}

The starting household and a backup-starting household were selected using satellite imagery and grids in Google Earth ${ }^{\mathrm{TM}} .{ }^{18}$ If teams deemed the starting household unsafe they proceeded to the backup-starting household. After the starting household, every other household was interviewed until 30 households were completed. A household was defined 
as a group of persons living together in a dwelling with a separate outer door and a separate kitchen. Most clusters had no household refusal. However, five clusters had a single refusal each.

Two teams of four trained Iraqi physicians worked with a supervisor and sampled households in May of 2014. Heads of household were identified and explained the survey procedure. After obtaining verbal informed consent, heads of the household were interviewed with regard to household demographics. Questions on injuries, mechanism, relation to conflict, care required, disabilities (e.g. ability to care for self, climb stairs, walk or suffering of pain, stigma or anxiety/depression), financial hardship, suspected responsible party for intentional injuries and others were asked. Subsequently, all household members were interviewed if present. The head of household provided information about injuries and disabilities for household members who were unable to answer questions (e.g. children, head injured) or not present.

\section{Data management and analysis}

Data were collected on paper forms and doubly entered into a database. Discrepancies were immediately clarified with collection teams. Age was divided into three categories: $₫ 4,15$ -64 , and $₫ 65$ years. The 15 years of age cut-off was defined by the minimum working age in Iraq. ${ }^{19}$ Over age 65 years, the risk of fall injury increases dramatically; thus, this age cutoff is used by the World Health Organization for age risk-stratification for fall injuries. ${ }^{2}$ We described the relationships between demographic factors and fall injuries. A non-parametric test for trend of the number of serious fall injuries per year was also calculated.

Bivariate logistic regression was used to model the effect of each covariate on having suffered a fall injury after 2002. After, a three-level mixed-effects logit link function was built in a bidirectional stepwise fashion. Age was included in the model given its known association with falling. ${ }^{2}$ Education level, occupation and fall location were included in the model given their evidence for strong association with fall injury from the bivariate analysis. None of the covariates demonstrated multicollinearity (mean variance inflation factor 1.13; condition number 11.6) and no influential outliers were identified. Akaike's information criteria (AIC) were used to measure the relative quality of each model. The use of age as a categorical covariate resulted in better model fit than when it was included as a continuous covariate. The model with the lowest AIC did not include sex, education level or workrelated injury. Covariates for cluster and household were included to control for intra-class correlation. The final model equation was:

$$
\text { Fall } \text { injury }_{i} \sim \beta_{0}+\beta_{\text {age }_{i}}+\beta_{\text {occupation }_{i}}+\beta_{\text {location }_{i}}+\mu_{\text {cluster }_{i}}+\mu_{\text {household }_{i}}
$$

Using national census data from 1997, 2003 and 2011 performed by the Iraqi Central Organization for Statistics and Information Technology, incidence rates were calculated. ${ }^{17}$ For years between censuses, the population of Baghdad was estimated using second-degree parabolic extrapolation. ${ }^{20}$ All analyses were performed using Stata v13 (College Station, TX, USA). 
To minimize reporting recall biased results, incidence rates were calculated using only serious injuries. Serious injuries were defined as those resulting in death, hospitalization or surgery or more than one month of selected disabilities (e.g. inability to care for self or walk as before the injury, suffering severe chronic pain or being unable to work due to anxiety or depression after injury). Further, a sensitivity analysis was performed to examine the proportion of reported injuries that resulted in death or ongoing disability. Non-fatal injuries with ongoing disability that occurred in 2014 were excluded in the sensitivity analysis given their potentially short duration. By comparing all reported fall injuries and serious fall injuries per year, conclusions can be drawn about potential recall bias.

\section{Ethics and funding}

Al Mustansiriya University and Baghdad Provincial Council approved the study. Approvals for secondary analysis of the de-identified database were obtained through Johns Hopkins Bloomberg School of Public Health and the University of Washington institutional review boards. Verbal informed consent was obtained from each head of household prior to interview and payment was not given to participants. No names or other identifying information were collected. Funding for logistics in Baghdad was provided by the United States based non-governmental organization, Surgeons OverSeas (SOS).

\section{Results}

\section{Number and rate of fall injuries}

Thirty randomly selected households from 30 clusters were surveyed, totaling 900 households and 5,148 individuals. There were 138 fall injuries, which comprised $25 \%$ of all reported injuries. Fall injuries were the most common cause of civilian trauma in postinvasion Baghdad. The rate of reported serious fall injuries may be increasing (Figure 1). To demonstrate this trend, there were 78 serious fall injuries per 100,000 persons in 2003; the rate increased to 233 per 100,000 in 2009 and to 466 per 100,000 in 2013 (non-parametric test for trend $p<0.001)$. The sensitivity analysis demonstrated that the rate of only fall injuries that resulted in death or ongoing disability also increased post-invasion from 58 per 100,000 persons in 2003 to 214 per 100,000 in 2013 (non-parametric test for trend $p=$ 0.003) (Supplementary Material).

\section{Fall injury epidemiology}

Fall injuries were equally common between genders; however, women had nearly twice the odds of having suffered a fall injury than men (74 vs 64 fall injuries among women and men, respectively; aOR 1.03, 95\% CI 0.59 - 1.81) (Table 1).

Fall was the most common mechanism among the injured elderly (i.e. $\ 65$ years; $15 / 24$ elderly unintentional injuries; 63\%) (Table 1). However, there was not evidence for greater odds of fall injury among the elderly compared to children aged $<15$ years from the multivariable model (aOR 0.73; 95\% CI $0.21-2.53$ ). Forty-six fall injuries were children aged $<15$ years ( $49 \%$ of unintentional injuries) and 77 fall injuries were respondents aged $\geq 15$ and $<65$ years (36\%). Respondents aged $15-64$ years were less likely to have suffered a fall injury compared to children (aOR 0.37 ; 95\%CI $0.14-0.97$ ). 
Most fall injuries occurred indoors; fall injuries sustained at home (90 fall injuries; 65\% of fall injuries) were more common than at an office or school (12; 9\%) (Table 1). Respondents who spent significant time within the home (i.e. unemployed, retired, homemaker) had more than three times the odds of having had a fall injury than students, who were used as referents (aOR 3.34; 95\% CI $1.30-8.60$ ). This was also evidenced by there being more fall injuries within the home than in public (aOR 5.12; 95\%CI $2.42-10.85$ ). Similarly, respondents had greater odds of having a fall injury at their office or in school than in public (aOR 6.98; 95\% CI 2.23 -21.87). There was not evidence for greater odds of fall injury among those working in industrial settings. Similarly, education level, marital status and work-related incident were not predictive of fall injury.

\section{Fall injuries and care}

The most common injuries after fall were orthopedic (e.g. fractures or dislocations; 79 fall injuries; 57 of fall injuries) (Table 2). Multiple injuries (30 fall injuries; $22 \%$ of fall injuries) and spinal cord and/or traumatic brain injuries $(21 ; 15 \%)$ were also reported. More than half of the fall injured sought care at a hospital (74 fall injured; 54\% of all fall injured) and 61 sought care at a clinic or by a nurse (44\%); only 1 respondent did not seek care (1\%). Thirtyfour fall injuries received inpatient care (25\% of fall injuries); however, 89 required some form of surgical care (i.e. outpatient and/or inpatient surgical care, such as closed reduction, suturing of laceration, external fixation, laparotomy; 65\%). Details on surgical care were not collected.

\section{Death and disability}

Although only 5 persons died as a result of falling ( $4 \%$ of falls), falls were responsible for $42 \%$ of all disabilities from unintentional injuries; 107 fall injured were left with some disability (78\%) (Table 2). Of those, 75 respondents were unable to care for themselves (54\% of fall injuries), 52 could not walk outside the home (38\%), 41 had chronic pain (30\%), and 25 had a psychological stress response that prevented return to pre-injury life (18\%) (Table 2).

\section{Household consequences of fall injury}

Fall injuries often affected the household. Nearly half of affected households (52 of 114 households; 46\%) witnessed a decline in household income and/or suffered food insecurity after a household member sustained a fall injury (Table 3). Thirty-four households had to borrow money to pay medical bills or recoup the injured's lost wages (30\% of affected households) and 21 households had to borrow 25 to $\geq 100 \%$ of the average Iraqi annual income to recover losses after fall injury (18\%). In Iraq, per capita income is US\$ 4,272 per year. ${ }^{11}$

\section{Discussion}

This study aimed to describe epidemiology, death and disability and household consequences after fall injuries in Baghdad to provide more robust estimates of the effect of conflict on civilian injury. Such estimates are vital for building an evidence base useful for injury control initiatives, formulating health policy and relief planning. Falls were the most 
common cause of civilian injuries in post-invasion Baghdad. Moreover, nearly $80 \%$ of those who sustained fall injuries were left with some form of disability. Subsequently, affected households often suffered financial hardship and food insecurity after a family member's fall injury. Therefore, fall injuries likely represent an important and often overlooked public health problem in LMICs, particularly among persons living amid conflict.

After road traffic injuries, falls are the leading cause of death from unintentional injury worldwide. ${ }^{2}$ Their incidence is increasing, mainly due to aging populations. ${ }^{21}$ In Baghdad, falls were a more frequent cause of unintentional injury than road traffic crashes, particularly among the elderly and children. These findings corroborate the high prevalence fall injuries among all ages found in a 2009 injury survey in Baghdad, despite a lower odds of fall injuries among adults aged $15-64$ years. ${ }^{4}$ While falls are common in LMICs, such a high incidence of fall injuries is not usually reported during peacetime (447 per 100,000 persons in 2013). ${ }^{4,14,22}$ For comparison, the reported rate of serious fall injuries from other Middle Eastern countries that have not been affected by recent conflict (e.g. United Arab Emirates, Iran, Qatar) ranges from 64 - 237 per 100,000 persons, even among high-risk groups (e.g. construction workers, elderly). ${ }^{23-25}$ Further, unlike other LMIC injury assessments, we found that women in Baghdad were not more commonly injured by falls than men. ${ }^{22,} 26$ All of these findings may be, in part, due to the disruption of safe infrastructure, behavior or protective environments for children caused by prolonged insecurity in Baghdad. ${ }^{4,27}$ Together, the unexpectedly high rate of fall injury and uncharacteristic distribution suggest that civilian fall injury epidemiology during conflict may differ substantially from that during peacetime.

Despite the large health burden that results from falls, only a small proportion of falls result in injury. An even smaller proportion of falls present to a health facility for care, and a smaller proportion of falls still are left with disability. ${ }^{2,28}$ In Baghdad, many respondents that were injured due to a fall were left with life-limiting disabilities. Almost $70 \%$ of those who suffered a fall injury were unable to perform their activities of daily living and nearly half were not able to leave the house after their injury. Respondents of all ages reported similar proportions of disabilities after fall injury, which suggests that the burden of disability among the elderly was not necessarily preexisting in older persons who fell as a result of their frailty. The high rate of disabilities amongst those with fall injuries might have been related to the effect of prolonged insecurity on the fragile health system in Baghdad. Iraq's health system remains beset by decades of war, sanctions, loss of health workers, looting and political interference. ${ }^{29}$ Emergency care, therapy and rehabilitation services are woefully inadequate for the volume of injury countrywide. ${ }^{30}$ Therefore, even minor injuries may lead to substantial disabilities. In addition to the prevention and treatment of acute injuries, significant investment into the rehabilitation of the injured should be considered when strengthening Iraqi health services or providing humanitarian assistance.

The injured's family often shouldered a significant burden of the trauma. In addition to lost income if an injured person was working, families of injured persons often cut back on their paid, house and school work to provide care or recoup financial losses. ${ }^{31}$ This study demonstrated that this was common in Baghdad, evidenced by a high proportion of affected families borrowing substantial sums of money for healthcare or to replace lost wages. 
Moreover, almost half of the affected households suffered food insecurity after a family member's fall injury. This highlights the importance of policies and programs designed to limit the cost of essential trauma care and aid the support systems of those temporary or chronically disabled from injury. In addition, the impact of injury on economic development cannot be overlooked and should serve as another incentive for supporting injury prevention and care in LMICs during relief and reconstruction efforts. ${ }^{32}$

This study is a large, comprehensive, community-based assessment of injuries in postinvasion Baghdad. However, the findings may be difficult to interpret for several reasons. First, five insecure clusters were replaced with more secure ones for the safety of study staff. These areas may have had a higher injury rate due to intense insecurity, particularly unsafe infrastructure or greater deviation from safe behavior. However, these clusters were replaced a priori and at random to minimize potential selection bias. Second, although Iraq has a vital registration and emergency department-based injury surveillance system, under-reporting of fatalities and poor documentation of non-fatal injuries is common worldwide, especially in LMICs strained by conflict. ${ }^{33,} 34$ Third, since 2003, there has been significant internal displacement and emigration for asylum and to seek medical care. Those most affected by the conflict or injured may have fled, thereby reducing the number of families reporting injury or death.

Another significant potential limitation is the risk of recall bias. While all surveys depend on the recall of respondents, our survey attempted to document injuries over a 10-year period. Fall injuries were reported as being more common now than immediately after the invasion. Though this may be true for reasons aforementioned, it might also reflect some degree of recall bias. Since respondents more frequently reported non-serious injuries from falls in recent years compared to distant years and with respect to serious fall injuries, this is almost certainly the case. However, falls without injuries and falls with minor injuries represent near misses. Identifying those at risk of future falls, particularly older persons, is important for reducing preventable death and disability. ${ }^{2,}{ }^{28}$ Nonetheless, to minimize this effect while reporting data from this study, we focused on serious injuries that were less likely to be forgotten as time passed. ${ }^{35}$ Given that the rate of serious fall injuries and the rate of only fall injuries that resulted in death or ongoing disability also increased significantly, these findings cannot be explained by recall bias alone. Next, the survey was conducted just prior to "Islamic State" insurgency within Iraq. It is possible that fall injury rates have changed as a result of the worsened security situation. Lastly, SOSINJ was developed to characterize the epidemiology of a number of injuries (i.e. it was not designed specially for falls). Therefore, data on fall history, functional status before the fall and the fall environment were not collected, limiting the analysis. Despite these limitations, these data allow important conclusions to be drawn about the burden and household consequences of fall injuries in Baghdad and the epidemiology of civilian fall injuries during conflict more broadly.

\section{Conclusion}

Fall injuries are the most common cause of civilian death and disability in Baghdad. In addition to the high incidence, fall injuries often result in significant disability that may be related to the effect of prolonged insecurity on a fragile healthcare system. ${ }^{4}$ In turn, affected 
households often bear the burden of injury through loss of income and food insecurity after a family member's fall injury. Opportunely, these findings highlight several possible targets for reducing the burden of civilian injury from falls during conflict. First, children and the elderly suffered from a particularly high number of fall injuries and disability. The disruption of the safe infrastructure and/or protective environments for children caused by protracted insecurity might be significant contributing factors. ${ }^{4} 7$ While rebuilding safe infrastructure is a difficult task, community-based health promotion for improving child supervision and supporting safe behavior may be more feasible. Second, essential trauma care and rehabilitation must be a healthcare planning and humanitarian relief priority. By doing so, the burden of disability found by this survey may be reduced by minimizing the long-term effects of future injury. Lastly, protecting affected households and support systems from the potentially devastating economic consequences of injury may prevent significant untold effects on uninjured household members. Given that there is little sign of conflict absolution in Iraq over the short-term, support of civilian injury control initiatives, trauma care strengthening efforts and indemnity for households of the disabled is urgently needed.

\section{References}

1. World_Health_Organization. The factsViolence and Injury Prevention. Geneva: 2010.

2. Kalache, A.; Fu, D.; Yoshida, S. WHO Global Report on Falls Prevention in Older Age.. In: SalasRojas, C., editor. Department of Aging and Life Course; World Health Organization; Geneva: 2007.

3. Lozano R, Naghavi M, Foreman K, Lim S, Shibuya K, Aboyans V, et al. Global and regional mortality from 235 causes of death for 20 age groups in 1990 and 2010: a systematic analysis for the Global Burden of Disease Study 2010. Lancet. 2012; 380:2095-2128. [PubMed: 23245604]

4. Donaldson RI, Hung YW, Shanovich P, Hasoon T, Evans G. Injury burden during an insurgency: the untold trauma of infrastructure breakdown in Baghdad. Iraq The Journal of trauma. 2010; 69:1379-1385. [PubMed: 21150518]

5. World_Health_Organization. Analysing Disrupted Health Systems in Countries in CrisesAnalysing Disrupted Health Sectors. Geneva: 2008.

6. Burnham G, Lafta R, Doocy S, Roberts L. Mortality after the 2003 invasion of Iraq: a crosssectional cluster sample survey. Lancet. 2006; 368:1421-1428. [PubMed: 17055943]

7. Hagopian A, Flaxman AD, Takaro TK, Esa Al Shatari SA, Rajaratnam J, Becker S, et al. Mortality in Iraq associated with the 2003-2011 war and occupation: findings from a national cluster sample survey by the university collaborative Iraq Mortality Study. PLoS medicine. 2013; 10:e1001533. [PubMed: 24143140]

8. Iraq Family Health Survey Study G. Alkhuzai AH, Ahmad IJ, Hweel MJ, Ismail TW, Hasan HH, et al. Violence-related mortality in Iraq from 2002 to 2006. The New England journal of medicine. 2008; 358:484-493. [PubMed: 18184950]

9. Roberts L, Lafta R, Garfield R, Khudhairi J, Burnham G. Mortality before and after the 2003 invasion of Iraq: cluster sample survey. Lancet. 2004; 364:1857-1864. [PubMed: 15555665]

10. GBD_Collaborators. Global, regional, and national age-sex specific all-cause and cause-specific mortality for 240 causes of death, 1990-2013: a systematic analysis for the Global Burden of Disease Study 2013. Lancet. 2015; 385:117-171. [PubMed: 25530442]

11. World_Bank_Group. Accounts ON. World Development Indicators. GNI per capita: Atlas method. 2014

12. Aboutanos MB, Baker SP. Wartime civilian injuries: epidemiology and intervention strategies. The Journal of trauma. 1997; 43:719-726. [PubMed: 9356079]

13. Chandran A, Hyder AA. Peek-Asa $C$ The global burden of unintentional injuries and an agenda for progress. Epidemiologic reviews. 2010; 32:110-120. [PubMed: 20570956] 
14. Stewart KA, Groen RS, Kamara TB, Farahzad MM, Samai M, Cassidy LD, et al. Traumatic injuries in developing countries: report from a nationwide cross-sectional survey of Sierra Leone. JAMA surgery. 2013; 148:463-469. [PubMed: 23325317]

15. Petroze RT, Joharifard S, Groen RS, Niyonkuru F, Ntaganda E, Kushner AL, et al. Injury, Disability and Access to Care in Rwanda: Results of a Nationwide Cross-Sectional Population Study. World journal of surgery. 2014

16. World_Health_Organization. Guidelines for Conducting Community Surveys on Injuries and Violence. Geneva: 2004.

17. Central Statistical Organization. General Census, Iraq, Republic of Iraq, Ministry of Planning. 2014

18. Galway L, Bell N, Sae AS, Hagopian A, Burnham G, Flaxman A, et al. A two-stage cluster sampling method using gridded population data, a GIS, and Google Earth(TM) imagery in a population-based mortality survey in Iraq. International journal of health geographics. 2012; 11:12. [PubMed: 22540266]

19. Coalition Provisional Authority Order 89. Amendments to the Labor Code. Iraq, Go, editor. Baghdad: 1987.

20. United_Nations. Estimates derviced by extrapolation of census results.Methods requiring three or more previous censuses. The United Nations; Geneva:

21. Wu S, Keeler EB, Rubenstein LZ, Maglione MA, Shekelle PG. A cost-effectiveness analysis of a proposed national falls prevention program. Clin Geriatr Med. 2010; 26:751-766. doi: 710.1016/ j.cger.2010.1007.1005. [PubMed: 20934620]

22. Mock CN, Abantanga F, Cummings P, Koepsell TD. Incidence and outcome of injury in Ghana: a community-based survey. Bulletin of the World Health Organization. 1999; 77:955-964. [PubMed: 10680242]

23. Abolhassani F, Moayyeri A, Naghavi M, Soltani A, Larijani B, Shalmani HT. Incidence and characteristics of falls leading to hip fracture in Iranian population. Bone. 2006; 39:408-413. [PubMed: 16510325]

24. Grivna M, Eid HO, Abu-Zidan FM. Epidemiology, morbidity and mortality from fall-related injuries in the United Arab Emirates. Scandinavian journal of trauma, resuscitation and emergency medicine. 2014; 22:51.

25. Asim M, El-Menyar A, Al-Thani H, Abdelrahman H, Zarour A, Latifi R. Blunt traumatic injury in the Arab Middle Eastern populations. Journal of emergencies, trauma, and shock. 2014; 7:88-96.

26. Hestekin, H.; O'Driscoll, T.; Williams, JS.; Kowal, P.; Peltzer, K.; Chatterji, S. WHO Study on Global AGEing and Adult Health (SAGE). World Health Organization; Geneva: 2013. Measuring prevlance and risk-factors of fall-related injuries in older aduls in low- and middle-income countries.

27. Devakumar D, Birch M, Osrin D, Sondorp E, Wells JC. The intergenerational effects of war on the health of children. BMC medicine. 2014; 12:57. [PubMed: 24694212]

28. Beattie BL. The National Falls Free Initiative, working collaboratively to affect change. J Safety Res. 2011; 42:521-523. doi: 510.1016/j.jsr.2010.1011.1009. Epub 2011 Nov 1017. [PubMed: 22152271]

29. Al Hilfi TK, Lafta R, Burnham G. Health services in Iraq. Lancet. 2013; 381:939-948. [PubMed: 23499042]

30. ICRC_Iraq. Giving disabled people a chance to resume a normal life. International Red Cross and Red Crescent; 2011.

31. Boden LI. Running on empty: families, time, and workplace injuries. American journal of public health. 2005; 95:1894-1897. [PubMed: 16195511]

32. Wesson HK, Boikhutso N, Bachani AM, Hofman KJ, Hyder AA. The cost of injury and trauma care in low- and middle-income countries: a review of economic evidence. Health policy and planning. 2014

33. Jacobs, G.; Aeron-Thomas, A.; Astrop, A. Vol. 445. Transport Research Laboratory; Crowthorne: 2000. Estimating global road fatalities. 
34. Toroyan, T.; Iaych, K.; Peden, M. Global Status Report on Road Safety: 2013Supporting a decade of action. World Health Organization: Department of Violence and Injury Prevention and Disability; Geneva: 2013.

35. Riddle MS, Tribble DR, Putnam SD, Mostafa M, Brown TR, Letizia A, et al. Past trends and current status of self-reported incidence and impact of disease and nonbattle injury in military operations in Southwest Asia and the Middle East. American journal of public health. 2008;

98:2199-2206. [PubMed: 18923114] 
40,000

Number of serious fall injuries

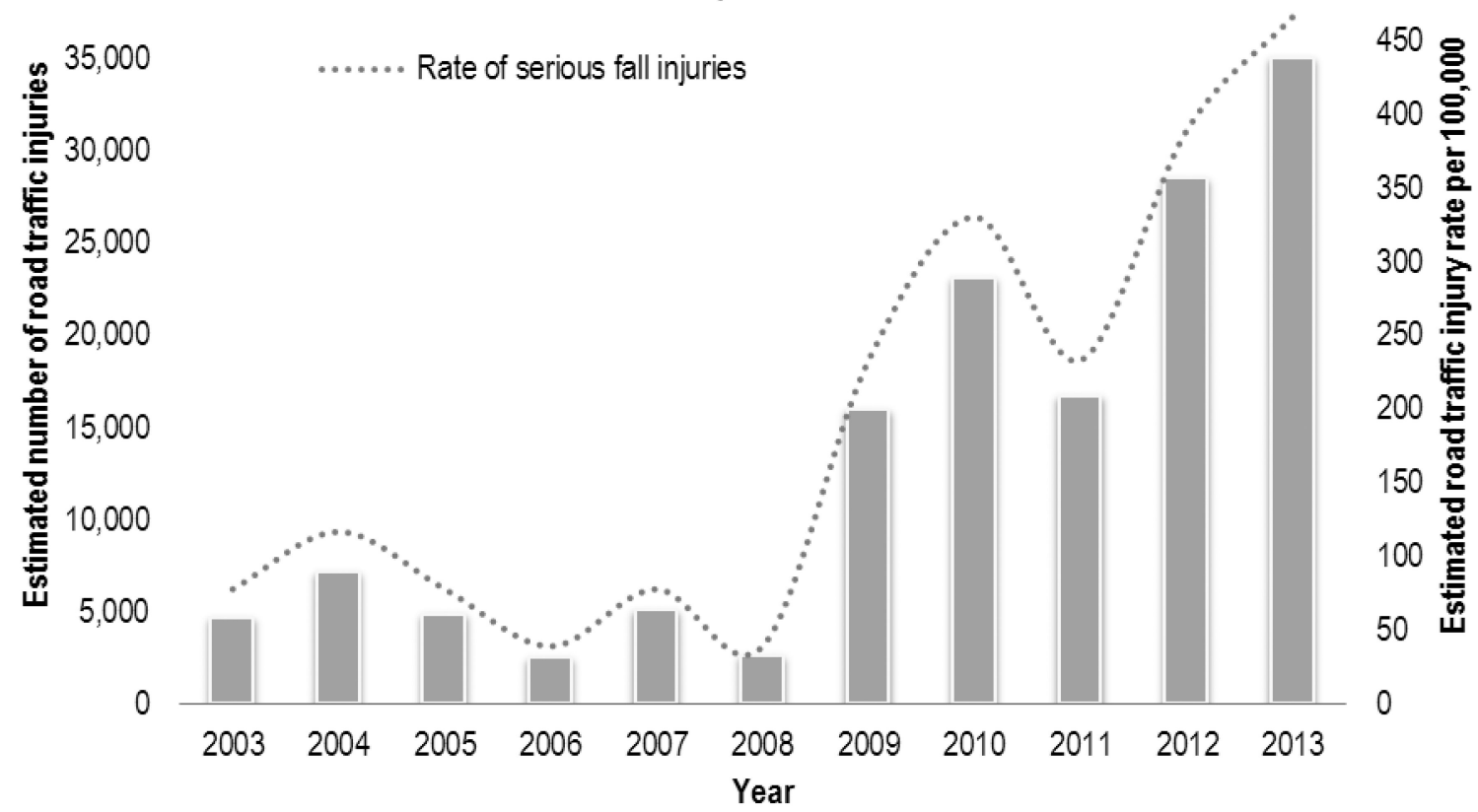

Fall injuries from 2014 are not included because data collection was in May; Serious fall injuries were defined as those resulting in death, hospitalization or surgery or more than one month of selected disabilities (i.e. inability to care for self or walk outside of the home, suffering chronic pain or being unable to work due to anxiety or depression after injury); non-parametric test for trend $\mathrm{p}<0.001$

Figure 1.

Estimated number and rate of serious fall injuries in Baghdad, Iraq from 2003 to 2013. 


\section{Table 1}

Demographic characteristics of surveyed household members and fall injured in Baghdad, Iraq from 2003-2014.

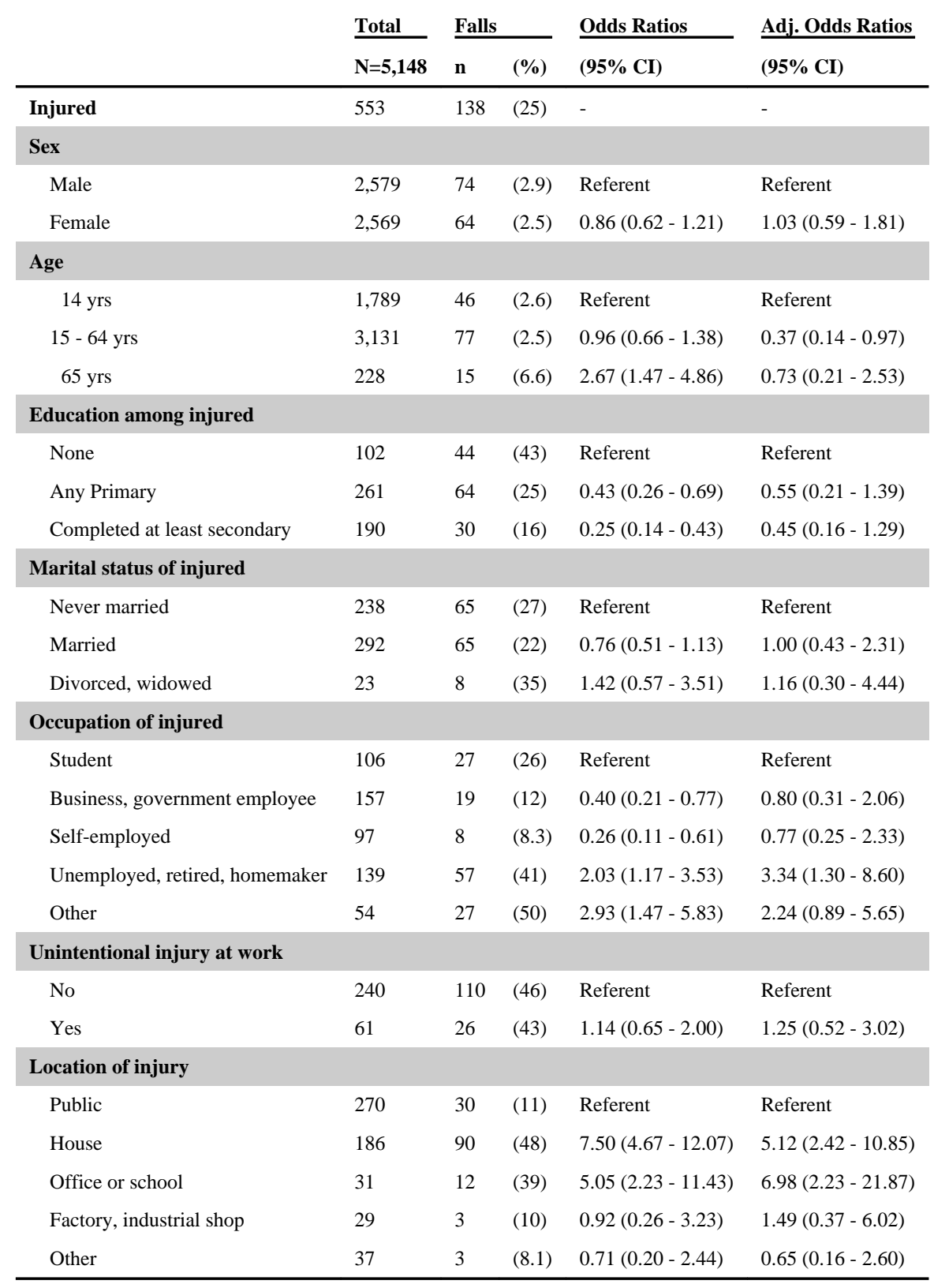

Adj. odds ratios from three-level multivariable mixed-effects logit link function with the covariates education level, occupation and fall location, as well as covariates for cluster and household to control for intra-class correlation 


\section{Table 2}

Clinical characteristics, death and disability from fall injuries in Baghdad, Iraq from 2003 to 2014 (N=137 fall injuries).

\begin{tabular}{|c|c|c|}
\hline & \multicolumn{2}{|c|}{ Fall injuries } \\
\hline & $\mathbf{n}$ & $(\%)$ \\
\hline \multicolumn{3}{|l|}{ Injury } \\
\hline Fracture or dislocation & 79 & (57) \\
\hline TBI or SCI & 21 & (15) \\
\hline Burn & 1 & (1) \\
\hline Polytrauma & 30 & (22) \\
\hline Unknown & 7 & (5) \\
\hline \multicolumn{3}{|l|}{ Initial site of care } \\
\hline Hospital & 74 & (54) \\
\hline Clinic & 61 & (44) \\
\hline Self-care & 1 & (1) \\
\hline \multicolumn{3}{|l|}{ Surgical care } \\
\hline Procedure(s) with anesthesia & 19 & (14) \\
\hline Procedure(s) without anesthesia & 70 & $(51)$ \\
\hline No procedure requires & 35 & (25) \\
\hline \multicolumn{3}{|l|}{ Hospitalization } \\
\hline Not hospitalized & 80 & $(58)$ \\
\hline$<2$ weeks & 37 & (27) \\
\hline$\geq 2$ weeks & 7 & (5) \\
\hline \multicolumn{3}{|l|}{ Death and disability } \\
\hline Died & 5 & (4) \\
\hline Alive without disability & 26 & (19) \\
\hline Alive with disability & 107 & (78) \\
\hline \multicolumn{3}{|l|}{ Disabilities } \\
\hline Needs assistance with self-care & 75 & (54) \\
\hline Unable to walk out of house & 52 & (38) \\
\hline Chronic pain & 41 & (30) \\
\hline Suffers social stigma & 80 & $(58)$ \\
\hline Anxiety, emotional changes & 25 & (18) \\
\hline Emotional changes preventing activity & 23 & (17) \\
\hline
\end{tabular}

TBI - traumatic brain injury; SCI - spinal cord injury 
Table 3

Household consequences of fall injuries in Baghdad, Iraq from 2003 to 2014 (N=114 affected households).

\begin{tabular}{lll} 
& \multicolumn{2}{c}{ Affected households } \\
\cline { 2 - 3 } & $\mathbf{n}$ & $(\%)$ \\
\hline Financial consequences & & \\
Decline in household income & 52 & $(46)$ \\
Decline in household food availability & 52 & $(46)$ \\
Borrowed money: USD & 34 & $(30)$ \\
$<250$ & 10 & $(8.8)$ \\
$250-999$ & 16 & $(14)$ \\
$1,000-4,999$ & 15 & $(13)$ \\
25,000 & 6 & $(5.3)$ \\
\hline
\end{tabular}

USD - United States dollars 